\title{
PDX-1 can repress stimulus-induced activation of the INGAP promoter
}

\author{
David A Taylor-Fishwick ${ }^{1,2}$, Wenjing Shi ${ }^{1}$, Gary L Pittenger ${ }^{1,3}$ \\ and Aaron I Vinik ${ }^{1,3}$ \\ ${ }^{1}$ Department of Medicine, Strelitz Diabetes Institutes, Eastern Virginia Medical School, Norfolk, Virginia 23510, USA \\ ${ }^{2}$ Department of Microbiology and Molecular Cell Biology, Eastern Virginia Medical School, Norfolk, Virginia 23510, USA \\ ${ }^{3}$ Department of Anatomy and Neurobiology, Eastern Virginia Medical School, Norfolk, Virginia 23510, USA \\ (Requests for offprints should be addressed to D A Taylor-Fishwick, Director - Cell and Molecular Biology, Strelitz Diabetes Research Institute, 855W. \\ Brambleton Ave., Eastern Virginia Medical School, Norfolk, VA 23510, USA; Email: taylord@evms.edu)
}

\begin{abstract}
Islet neogenesis associated protein (INGAP) promotes the generation of new islet mass in adult animal models. It is not understood what factors control the expression of INGAP. In this study, factors that regulate the expression of INGAP promoter activity are reported. To determine factors that regulate INGAP expression, we previously cloned the promoter region for INGAP. Analysis of the INGAP promoter suggested that candidate regulators of INGAP expression include the transcription factors PDX-1, NeuroD, PAN-1, STAT and AP-1. Using gene addition experiments in the 293 cell line the activity of these transcription factors on an INGAP-promoter construct linked to the $\beta$-galactosidase reporter has been determined. Induction of AP-1 activity or STAT activity using PMA or LIF stimulation respectively, or direct expression of PAN-1 specifically up-regulates INGAP promoter activity. In contrast, co-expression of PDX-1 but not NeuroD inhibits activation of the INGAP-promoter
\end{abstract}

driven by PAN-1, PMA or LIF stimulation. PDX-1 binds directly to the INGAP promoter as determined in electromobility shift and antibody supershift assays. Expression of the INGAP-promoter-reporter construct in the HIT-T15 beta-cell line, a cell line that expresses endogenous PDX-1, did not reveal PMA-mediated stimulation of INGAP promoter activity. HIT-T15 cells however did efficiently transfect $(>68 \%)$ and respond (2-fold) to PMA-induced signal transduction to a transfected AP-1CAT reporter. Partial reduction of PDX-1 expression in HIT-T15 cells was associated with recovery of PMA induced INGAP promoter activity. These data suggest that expression of PDX-1 is associated with a repression of stimulus-induced INGAP promoter activity that appears to be mediated by a direct DNA interaction. These findings implicate PDX-1 in a possible feedback loop to block unbridled islet expansion.

Journal of Endocrinology (2006) 188, 611-621

\section{Introduction}

The pathogenesis of both type 1 and type 2 diabetes is linked to a loss of functional pancreatic beta-cell mass (Bell \& Polonsky 2001). In type 1 diabetes, beta-cells are actively removed in an autoimmune attack (Mathis et al. 2001 ) and a reduction of approximately $50 \%$ of the beta-cell mass has occurred at the diagnosis of type 2 diabetes (UKPDSGroup 1995) with a proceeding annual loss of $5-10 \%$ of the beta-cell mass. The restoration of functional beta-cell mass is an important concept in treating diabetes. Transplantation of donor islets can reverse diabetes (Ryan et al. 2002), however this approach has serious limitations rooted in an inadequate donor supply and drug toxicity related to long-term immunosuppression (Hirshberg et al. 2003). An alternative approach is to drive adult stem cells residing in the pancreas to restore the functional islet mass. Adult islet mass can be enhanced both by replication of existing islets (BonnerWeir et al. 1993, Dor et al. 2004) and by neogenic commitment of precursor cells to new islets (Rosenberg et al. 1989, Bonner-Weir et al. 1993, Li et al. 2002, Peters et al. 2005). This latter process is termed islet neogenesis. Pathways governing islet neogenesis are poorly understood, although the process can be regulated through the administration of bio-active factors such as islet neogenesis associated protein (INGAP) (Rosenberg et al. 2004, Vinik et al. 2004), GLP-1 (exendin) (Holz \& Chepurny 2003), Clusterin (Kim et al. 2001), REG (Okamoto 1999) and Gastrin/EGF (Brand et al. 2002). Several of these factors are undergoing clinical trials.

The bioactive factor, islet neogenesis associated protein (INGAP) was first identified as a differentially expressed gene in a hamster model of islet neogenesis (Rafaeloff et al. 1997). Administration of INGAP protein to hamsters elevated endogenous beta-cell mass sufficiently to decrease 
hyperglycemia in drug-induced diabetes (Vinik et al. 2004). Endogenous INGAP expression is concomitant with the induction of islet neogenesis (Del Zotto et al. 2000). The INGAP protein has a molecular weight of $16.8 \mathrm{KDa}$ and is related to the type 2 C-lectins (TaylorFishwick et al. 2003, Vinik et al. 2004). The organization of the 175 amino acids of INGAP classifies it as a member of the group 2 superfamily of reg-related proteins (Okamoto 1999). In addition to the biological efficacy of the INGAP protein, a pentadecapeptide derived from the INGAP holoprotein has been identified which retains biological activity. The exogenous administration of INGAP peptide stimulates islet neogenesis in rodents (Rosenberg et al. 2004) and dogs (G L Pittenger and D A Taylor-Fishwick, unpublished observations). Moreover, INGAP peptide can reverse diabetes in established streptozotocin-induced diabetic-C57BL6 mice (Rosenberg et al. 2004). The bioactivity of INGAP is further demonstrated in the enhancement of the beta-cell secretory response by administration of INGAP peptide (Borelli et al. 2005) and in the ability of INGAP to promote duct to islet transdifferentiation in vitro (Jamal et al. 2005).

The molecular events regulating endogenous expression of INGAP are unclear and insight into these pathways has come from the recent cloning of the INGAP 5-prime regulatory region (Taylor-Fishwick et al. 2003). The regulatory region of INGAP has, in addition to transcriptional elements resulting from conventional signaling pathways including AP-1 and STAT, a number of predicted interaction sites for transcription factors associated with pancreas development. These include the homeodomain transcription factor PDX-1, inactivation of which results in agenesis of the pancreas (Jonsson et al. 1994, Stoffers et al. 1997), and the basic helix-loop-helix transcription factors NeuroD/Beta2 (Huang et al. 2000) and PAN-1(E47) (German \& Wang 1994). NeuroD is an essential pathway in endocrine development (Naya et al. 1997) and PAN-1 is a binding partner for NeuroD (Mutoh et al. 1997) having the ability to bind to the insulin promoter to transactivate the insulin gene (Dumonteil et al. 1998).

In this report we describe the functional integration of PDX-1 to regulate INGAP-promoter mediated expression. Specifically, while PDX-1, PAN-1, AP-1 and STAT stimulate the INGAP-promoter, PDX-1 exerts an inhibitory effect on factors shown to induce INGAP gene expression. This study provides the first evidence for a simple regulatory feedback loop to prevent unrestrained expansion of islet mass.

\section{Material and Methods}

\section{Cell culture}

Cell lines were obtained from American Type Culture Collection (ATCC, Manassas, VA, USA). The human embryonic kidney cell line, 293, was cultured in DMEM (Invitrogen) containing 10\% FBS (Invitrogen). The hamster pancreatic beta-cell line, HIT-T15 (p65-69), was cultured in RPMI1640 containing $2 \mathrm{mM}$ L-glutamine, $1.5 \mathrm{~g} / 1$ sodium bicarbonate (ATCC), $10 \%$ horse serum (Invitrogen) and $2.5 \% \mathrm{FBS}$ at $37^{\circ} \mathrm{C}$. Cells were cultured at $37^{\circ} \mathrm{C}$ in a $5 \% / 95 \% \quad \mathrm{CO}_{2} /$ air humidified atmosphere. Cells were passaged using $0 \cdot 25 \%$ trypsin-EDTA (Invitrogen).

\section{Plasmids and antibody}

Sequential deletions of the INGAP promoter were constructed as previously described (Taylor-Fishwick et al. 2003). All fragments were digested with XmaI and BglII (New England Biolabs, Beverly, MA, USA) and subcloned into the $\mathrm{p} \beta$ gal-basic vector (Clontech), a promoterless $\beta$-galactosidase expression vector. The first start codon ATG downstream of the TATA-box in the reporter gene construct is that for $\beta$-galactosidase. The p32-1-1CAT reporter-plasmid, containing repeated AP-1 binding sites upstream of a CAT reporter, was generously provided by Dr Timothy Bos (Department of Microbiology and Molecular Cell Biology, EVMS, Norfolk, VA, USA). Expression plasmids for PDX-1, NeuroD and PAN-1; pBAT12 shPDX-1, pBAT12 mNeuroD and pBAT14 shPan-1 were generously provided by Dr Michael German (Hormone Research Institute, UCSF, CA, USA). The green fluorescent protein expression plasmid (pCMV-GFP) was obtained from Clontech. For Western blotting, the primary antibodies used were rabbit anti-PDX-1 (Chemicon International Inc., Temecula, CA, USA), anti-NeuroD (N-19) and anti-PAN-1 (N-649) (both Santa Cruz Biotechnology, Santa Cruz, CA, USA). Anti-PDX-1(N-18) and anti-STAT3 (F-2) (Santa Cruz Biotechnology) were used in the EMSA as specific and non-specific PDX-1 antibodies respectively.

\section{Transient transfection and PMA stimulation}

Transient transfections of 293 and HIT-T15 cells were carried out using LipofectAMINE reagent (Invitrogen). Briefly, $4 \times 10^{5}$ cells were cultured overnight in sixwell $(35 \mathrm{~mm})$ tissue culture plates (Corning Inc., Corning, NY, USA). The following day, plasmids $\left(1 \mu \mathrm{g} / 4 \times 10^{5} \mathrm{cells}\right)$ and LipofectAMINE reagent $(10 \mu \mathrm{l} /$ $4 \times 10^{5}$ cells) were each diluted in $0.75 \mathrm{ml}$ serum-free medium then combined, mixed and incubated at room temperature for $30 \mathrm{~min}$. Following $30 \mathrm{~min}$, cells in $1.5 \mathrm{ml}$ serum-free medium, were added to the transfection mixture and cultured for $5 \mathrm{~h}$ at room temperature. Cells were then removed and placed in serum-containing media being cultured for $48-72 \mathrm{~h}$. For induction studies, the transfected cells were stimulated with $50 \mathrm{ng} / \mathrm{ml}$ PMA (Sigma) or $10 \mathrm{ng} / \mathrm{ml}$ hLIF (Sigma) on the day following transfection. To normalize transfection efficiency, cells 
were co-transfected with pAP4 (Flanagan \& Cheng 2000), a secretory alkaline phosphatase expression plasmid kindly provided by Dr John Flanagan (Harvard, MA, USA). The substrate pNPP (Sigma) was used to determine secretory alkaline phosphatase activity in cell culture supernatant that had been heat inactivated at $70{ }^{\circ} \mathrm{C}$ for $10 \mathrm{~min}$ to destroy endogenous alkaline phosphatase activity.

\section{$\beta$-galactosidase reporter gene assay}

After-transfection (48-72 h), cells were harvested and washed twice with PBS (Invitrogen). Cells were lysed using a combination of lysis buffer $\left(100 \mathrm{mM} \mathrm{K}_{2} \mathrm{HPO}_{4}\right.$, $100 \mathrm{mM} \mathrm{kH}{ }_{2} \mathrm{PO}_{4}, 1 \mathrm{mM}$ DTT), and three freeze-thaw cycles. The lysate was centrifuged in a microcentrifuge at $16100 \times \boldsymbol{g}$ for $10 \mathrm{~min}$ to clear the lysate supernatant. Activity of $\beta$-galactosidase was determined using a chemiluminescence-based kit (Clontech). Briefly, $25 \mu$ of the cell lysate was reacted with $200 \mu$ of $\beta$-galactosidase chemiluminescence reaction buffer (Clontech) per well of a white opaque 96-well plate (Fisher, Pittsburgh, PA, USA) for one hour at room temperature. The luminescence value was read on a Wallac Victor ${ }^{2} 1420$ multilabel counter (PerkinElmer Life Sciences, Downers Grove, IL, USA). Proteins were normalized to protein concentration determined using the Bradford method (Bradford 1985) (Bio-Rad). Increase in luminescence for the INGAPpromoter reporter is expressed relative to transfection of the promoterless $\beta$-galactosidase reporter (pBASIC), that is, where the INGAP-promoter was omitted.

\section{CAT ELISA assay}

The expression of the chloramphenicol acetyltransferase (CAT) reporter gene was determined using a CAT ELISA kit (Roche). Following manufacturers directions, cells were washed three times in PBS (Invitrogen) and lysed at room temperature for $30 \mathrm{~min}$. The cleared lysate $(200 \mu \mathrm{l}$; $15 \mathrm{~min}$ at $16100 \times \boldsymbol{g}$ ) was added to separate wells of a 96-well microtitre plate precoated with anti-CAT. Presence of CAT was detected by anti-CAT digoxigenin and anti-digoxigenin-peroxidase before being visualized with ABTS- 2,2'-azino-bis(3-ethylbenzthiazoline-6sulfonic acid)-substrate. All incubations were for $1 \mathrm{~h}$ at $37^{\circ} \mathrm{C}$. Colorimetric changes were read at $405 \mathrm{~nm}$ on a Wallac Victor ${ }^{2} 1420$ multilabel counter (Perkin Elmer).

\section{Flow cytometery assay}

Both mock and pCMV-GFP (Clontech) transfected HITT15 cells were trypsinized, harvested by centrifugation and washed three times with cold PBS. Cell pellets were resuspended in $500 \mu \mathrm{l}$ cold PBS and cell fluorescence determined by flow cytometry (FACSCalibur, Becton Dickinson, CA, USA). A minimum of 20000 events per sample were acquired during analysis. Cells falling into a preset gate for fluorescent positive cells were expressed as a percentage of the total live cells acquired. Transfected cells in culture were viewed on an Olympus IX70 Confocal Microscope and scanned for brightfield and fluorescence.

\section{Western blotting}

Nuclear and cytoplasmic proteins were extracted using NE-PER nuclear and cytoplasmic extraction reagent kit (Pierce, Rockford, IL, USA) containing Halt protease inhibitor cocktail (Pierce). Protein samples were mixed with an equal volume of SDS sample buffer (50 mM Tris-HCl pH6.8, 2\% SDS, 15\% glycerol, 5\% $\beta$-mercaptoethanol, 0.001\% Bromophenol blue), and heated at $85{ }^{\circ} \mathrm{C}$ for $2 \mathrm{~min}$. The denatured proteins were resolved on $12 \%$ Novex pre-cast Tris-glycine gel (Invitrogen) at $125 \mathrm{~V}$ for $90 \mathrm{~min}$ and transferred to Hybond-ECL nitrocellulose membrane (Amersham Biosciences) by electro elution in transfer buffer $(192 \mathrm{mM}$ Glycine, $25 \mathrm{mM}$ Tris-base, 20\% methanol) at $30 \mathrm{~V}$ for $90 \mathrm{~min}$. Membranes were blocked with 5\% (w/v) non-fat milk (Richfood Inc., Richmond, VA, USA) in TBS-T buffer (Sigma; $50 \mathrm{mM}$ Tris pH8.0, $138 \mathrm{mM} \mathrm{NaCl}$, $2.7 \mathrm{mM} \mathrm{KCl}$ containing $0 \cdot 1 \%$ Tween 20 ) at $4{ }^{\circ} \mathrm{C}$ overnight. Following a wash in TBS-T buffer, membranes were incubated for $1 \mathrm{~h}$ at room temperature in TBS-T buffer containing 1\% non-fat milk and 1:5000 rabbit anti-PDX-1. After three washes in TBS-T buffer, membranes were incubated for $1 \mathrm{~h}$ at room temperature in TBS-T buffer containing 1:25000 donkey anti-rabbit $\operatorname{IgG}$ antibody conjugated to horseradish peroxidase (Amersham Biosciences). Proteins were detected using ECL plus Western blotting detection reagents as per manufactures instructions (Amersham Biosciences) and visualized by autoradiography on BioMax Light film (Sigma) for $5 \mathrm{~min}$. The films were developed using Futura $3000 \mathrm{~S}$ automatic film processor (Diagnostic Imaging Inc. Winston-Salem, NC, USA)

\section{Electrophoresis mobility shift assay (EMSA)}

Nuclear extracts were prepared as described above. DNA probe (nucleotides 446-680 bp of Genbank sequence AY184211) was excised from the INGAP promoter plasmid using XmnI and Tsp509I (New England Biolabs), restriction digests being purified using the QIAquick-gel extraction kit (QIAGEN) as per manufacturer's instructions. The probe was labeled with biotin using biotin $3^{\prime}$-end DNA labeling kit (Pierce). Nuclear extracts were incubated with 20 fmole biotinylated probe at room temperature for $30 \mathrm{~min}$ in binding buffer (Pierce, $100 \mathrm{mM}$ Tris pH 7·5, $500 \mathrm{mM} \mathrm{KCl}, 10 \mathrm{mM}$ DTT, 50\% glycerol, $100 \mathrm{mM} \mathrm{MgCl} 2,1 \mu \mathrm{g} / \mu \mathrm{l}$ poly(dI:dC), 1\%NP-40, $1 \mathrm{M} \mathrm{KCl})$. Unbiotinylated DNA probe $(2$ pmole) was preincubated for $10 \mathrm{~min}$ in competition experiments. The 


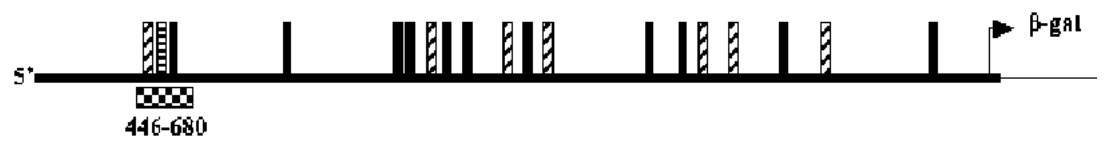

Figure 1 Schematic diagram of the INGAP-promoter-reporter construct. The relative location of predicted binding sites for PDX-1 (filled), NeuroD (lined) and PAN-1 (striped) on the INGAP regulatory region are shown. Nucleotide region, 466-680 is marked (checkered).

samples were electrophoresed at $100 \mathrm{~V}$ being separated on a $4 \%$ polyacrylamide gel in $0.5 \times \mathrm{BE}$ buffer $(4.5 \mathrm{mM}$ Tris-base pH8.0, $4.5 \mathrm{mM}$ Borate, $1 \mathrm{mM}$ EDTA) for $90 \mathrm{~min}$. Protein complexes were transferred to Nylon membrane (Pierce), and DNA was crosslinked to the membrane under u.v. light for 8 min. Biotin-labeled DNA was detected using the LightShift Chemiluminescent EMSA kit (Pierce) following the manufacturer's instructions and visualized by autoradiography. Alternatively, the probe was labeled with $\left[\alpha-{ }^{32} \mathrm{P}\right]$ ATP (PerkinElmer, Boston, MA, USA) by incubating with T4 polynucleotide kinase using the DNA $5^{\prime}$-end labeling system (Promega). The labeled probe $(40000$ c.p.m.) was added to reactions as described above. Following electrophoresis, gels were dried and bands detected by autoradiography or phosphoimager analysis using a Typhoon9410 scanner (Molecular Dynamics, Sunnyvale, CA, USA). Image Quant (Molecular Dynamics) software was used for quantification.

Construction and transfection pSilencer2-0-U6-PDX-1siRNA: Hairpin siRNA for hamster PDX-1 mRNA (U73854) sense sequence 573-593 (GCUGGAGAAG GAAUUCUUATT) and antisense sequence 571-589 (UAAGAAUUCCUUCUCCAGCTC) was designed by Ambion Inc. Austin, Texas, USA. Oligonucleotides, 5'GATCCGCTGGAGAAGGAATTCTTATTCAAGA GATAAGAATTCCTTCTCCAGCTCTTTTTTGGA AA3'and 3'GCGACCTCTTCCTTAAGAATAAGTTC TCTATTCTTAAGGAAGAGGTCGAGAAAAAACCT TTTCGA5' (Intergraded DNA Technologies, Inc. Coralville, IA, USA) were annealed at $94^{\circ} \mathrm{C}$ for 2 mins, and cooled to room temperature. The resulting dsDNA was directionally cloned into pSilencer2.0-U6 vector (Ambion Inc.) using the incorporated restriction sites BamHI and HindIII to form pSilencer2.0-U6-PDX-1-CsiRNA. For transfection of pSilencer2-0-U6-PDX-1-CsiRNA, $6 \times 10^{5}$ HIT-T15 cells were plated into 6-well (35 mm) plates (Corning), and incubated for two days before transfections. On the day of transfections, pSilencer2-0-U6-PDX-1-C-siRNA and INGAP promoterreporter plasmid were co-transfected into HIT-T15 cells using lipofectamine2000 (Invitrogen). Cells were stimulated and assayed as described above.

Results are shown as mean \pm S.E.M. Significance of the data was evaluated by non-paired Student's $t$-test. $P<0 \cdot 05$ was judged significant. Analyses were performed using
Graphpad prism V4·0 software (Graphpad Software Inc., San Diego, CA, USA).

\section{Results}

Recent cloning of the genomic sequence for INGAP has identified promoter activity that is responsive to defined biochemical stimuli (Taylor-Fishwick et al. 2003). Potential binding sites for PDX-1, a homeobox transcription factor, for PAN-1 a ubiquitous class A basic helix-loophelix transcription factor and for NeuroD a class B basic helix-loop-helix transcription factor were identified upstream to the transcriptional start site for the INGAP gene. As illustrated in Figure 1, a search on Genomatix Mat Inspector professional 6.0 (Cartharius et al. 2005; Genomatix Software GmbH, Munich, Germany) identified eleven PDX-1, one NeuroD and seven PAN-1(E47) predicted binding sites within the $3 \mathrm{Kbp}$ region upstream of the INGAP transcriptional start site. The location of these predicted sites are marked in Fig. 1 in relation to the transcriptional start site for INGAP. At the gene location 446-680, NeuroD, PDX-1 and PAN-1 co-cluster.

The transcription factors PDX-1, NeuroD and PAN-1 were expressed in 293 cells, either alone or in combination, to determine if they had an active role in regulating the reporter gene expression driven by the INGAP promoter. Expression plasmids for each defined transcription factor and an INGAP-promoter-reporter plasmid were co-transfected into 293 cells. Expression of the factor was confirmed by Western blot analysis (data not shown). The human embryonic kidney epithelial cell line, 293, has no detectable expression of endogenous INGAP and can support INGAP-promoter reporter gene expression in response to defined exogenous stimuli (Taylor-Fishwick et al. 2003). The ability of each transcription factor to activate the INGAP promoter was measured by the production of the reporter gene, $\beta$-galactosidase using a luminescence-based assay. Specificity for INGAP promoter activation was confirmed by substituting the INGAP-promoter reporter gene with a promoterless $\beta$-galactosidase reporter-gene. The data shown is expressed as the fold induction over the promoterless reporter gene activity. Introduction of the PDX-1 expression plasmid into cells resulted in a two-fold increase in INGAP-promoter regulated $\beta$-galactosidase activity. 


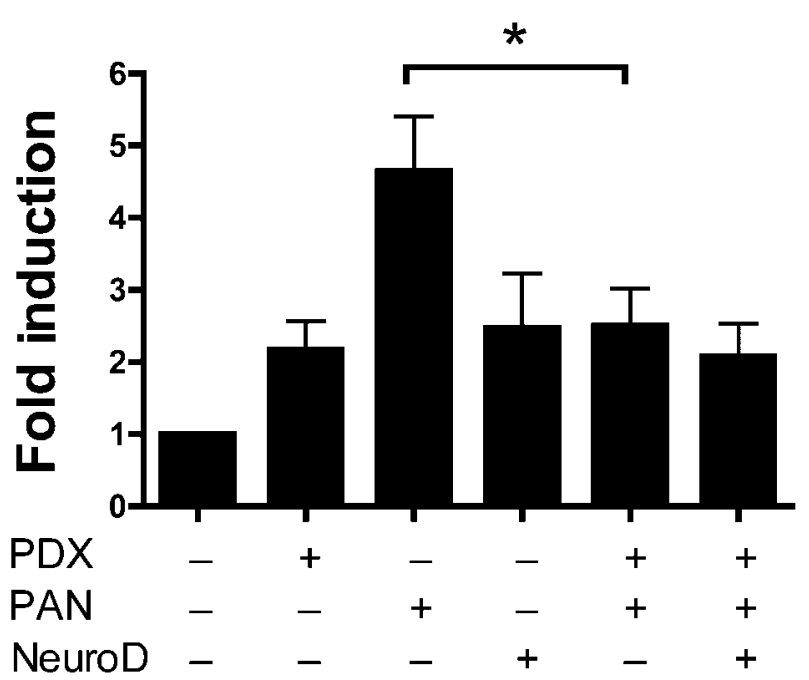

Figure 2 Fold induction of $\beta$-galactosidase reporter gene activity in response to transcription factors. 293 cells transfected with the promoterless $\beta$-galactosidase reporter or INGAP-promoter $\beta$-galactosidase reporter were co-transfected with PAN-1, PDX-1, NeuroD and combinations as labeled. Data shows INGAPpromoter mediated $\beta$-galactosidase activity expressed as a fold induction over the $\beta$-galactosidase activity of the promoterless reporter construct. Significant reduction in PAN-1-induced reporter activation in marked $\left({ }^{*} P<0 \cdot 05\right)$

Introduction of the NeuroD expression plasmid into cells resulted in a two-fold increase in INGAP-promoter regulated $\beta$-galactosidase activity. In contrast, introduction into 293 cells of the expression plasmid for the ubiquitous transcription factor PAN-1(E47) resulted in a five-fold increase in INGAP-promoter regulated $\beta$-galactosidase activity. Additionally, the consequence of combining transcription factors was explored. Expression plasmids for multiple transcription factors along with the INGAP-promoter-reporter plasmid were simultaneously transfected. PDX-1 expressed along with PAN-1 resulted in a significant $(P<0 \cdot 05, t$-test $)$ reduction in INGAP promoter reporter gene activity when compared with PAN-1 alone. The fold induction with the PAN-1/ PDX-1 combination was equivalent to that seen with PDX-1 alone indicating that the PAN-1 response had been blocked. This was seen as a specific effect and not due to relative dilution of plasmid since no significant $(P>0.05, t$-test) inhibition of PAN-1(E47) stimulating activity was observed in the co-transfection of NeuroD or the empty plasmid (not shown). Combining PDX-1 and NeuroD (not shown) did not result in a significant change in $\beta$-galactosidase activity when compared with cells transfected with either factor alone. The expression plasmids for both NeuroD and PDX-1 share the same plasmid backbone. Transfection of all three factors, PAN-1, NeuroD and PDX-1 also revealed an inhibition of the PAN-1(E47) mediated stimulation (Fig. 2).
In order to determine if the PDX-1 inhibition was restricted to PAN-1 stimulation or provided a general block of stimulation, the effect of PDX-1 on PMA and LIF stimulation of the INGAP promoter was tested. We have previously shown that both the phorbol ester PMA (Taylor-Fishwick et al. 2003) and the cytokine LIF (Taylor-Fishwick et al. 2002) stimulate INGAP-promoter activity in transfected 293 cells. The 293 cell line was co-transfected with the INGAP-promoter-reporter construct and with either the expression plasmid pBAT12 PDX-1 encoding for PDX-1, or the expression plasmid pBAT12 NeuroD encoding for NeuroD to provide an expression plasmid control. Following transfection, cells were stimulated with $50 \mathrm{ng} / \mathrm{ml}$ PMA for $24 \mathrm{~h}$ and the activity of the reporter gene assayed. The PMA-induced stimulation of the INGAP-promoter-reporter in control 293 cells was compared with the PMA-induced stimulation of the INGAP-promoter-reporter in 293 cells expressing PDX-1. In control 293 cells PMA stimulated a greater than three-fold induction of $\beta$-galactosidase activity (Fig. 3A). Whereas the presence of PDX-1 inhibited the PMA-induced stimulation of $\beta$-galactosidase driven by the INGAP promoter $(P<0 \cdot 05, t$-test). This inhibition was not observed in cells transfected with NeuroD (Fig. 3A). The NeuroD expressing cells showed the equivalent three-fold induction in promoter activity in response to PMA. The expression of PDX-1 protein in 293 cells transfected with pBAT12 PDX-1 was confirmed by Western Blot analysis (Fig. 3A, inset). Control 293 lysate (lane a) did not have a PDX-1 immuno-reactive band whereas lysate from cells transfected with PDX-1 (lane b) did have a PDX-1 immuno-reactive band. Similarly, there was a 2.5 fold induction of INGAP-promoter activity stimulated by LIF in control 293 cells. This stimulation was inhibited by $50 \%(P<0 \cdot 05, t$-test $)$ in 293 cells expressing PDX-1 (Fig. 3B). Thus the negative action of PDX-1 on INGAP gene regulation extends to both PMAmediated and LIF-mediated stimuli and is not restricted to stimulation of the INGAP-promoter mediated by the transcription factor PAN-1 in the 293-transfection model.

To confirm that PDX-1 interacts directly with the INGAP promoter, EMSA was performed. Region 466680 (Genbank AY184211) of the INGAP promoter (marked in Fig. 1) was biotinylated and used as a binding probe on nuclear extracts from 293 cells (control) and 293 cells that had been transfected with pBAT12 PDX-1, the PDX-1 expression plasmid. A shifted band was detected that was specific for the PDX-1 expressing 293 nuclear extract (Fig. 4A, lane a). Furthermore, the band-shift was blocked in conditions where the nuclear extracts were incubated with both biotinylated probe and a 50-fold molar excess of unbiotinylated probe (Fig. 4A, lane $\mathrm{b})$. Additionally, to demonstrate that the shifted complex contained PDX-1, an antibody mediated supershift experiment was performed. In the presence of the PDX-1 antibody the specific complex migrated at a 


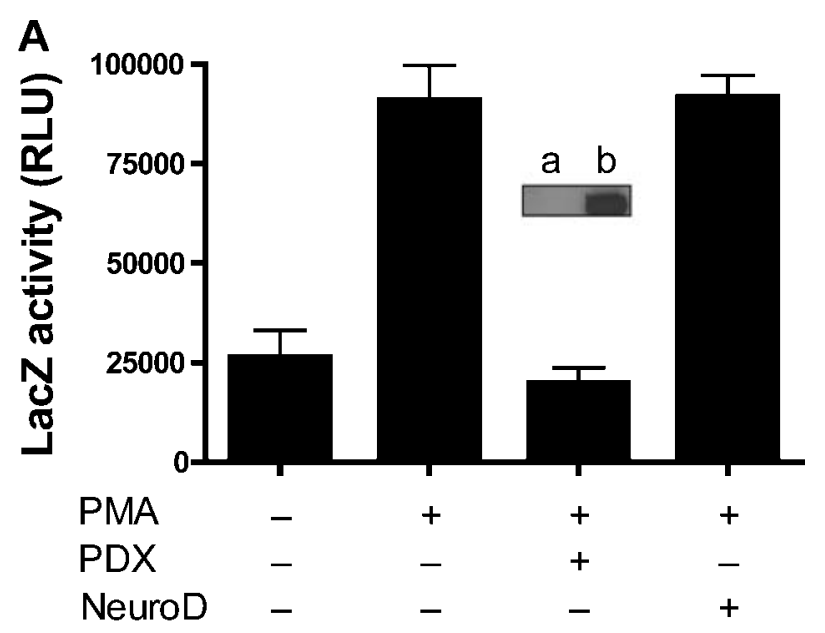

A

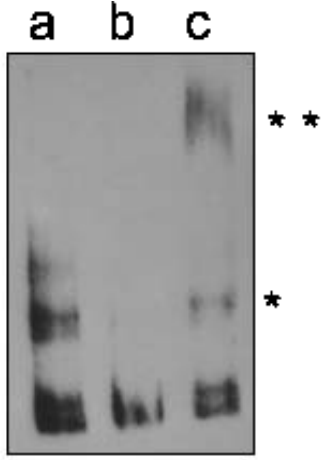

B

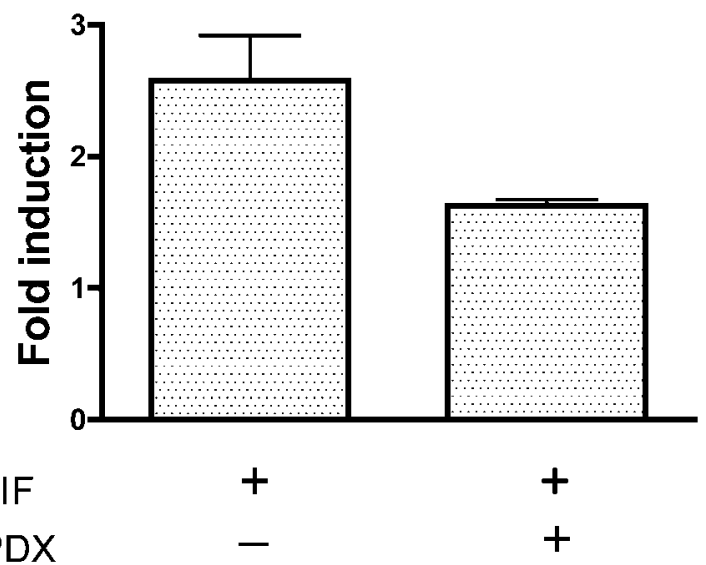

Figure 3 PDX-1 inhibits stimuli of the INGAP promoter. Mock transfected 293 cells were compared with 293 cells transfected with PDX-1 or NeuroD. The cells were stimulated with $50 \mathrm{ng} / \mathrm{ml}$ PMA (A) or $10 \mathrm{ng} / \mathrm{ml}$ LIF (B). Inset (A) shows Western blot analysis for PDX-1 expression in 293 cells (a) or 293 cells transfected with PDX-1 (b). Data shows $\beta$-galactosidase reporter gene activity $(A)$ and fold induction $(B)$ relative to the promoterless $\beta$-galactosidase reporter.

higher molecular mass confirming the presence of PDX-1 in the INGAP-promoter complex (Fig. 4A, lane c). This supershift was not observed in extracts incubated with a non-PDX-1 recognizing antibody (Fig. 4B). Therefore PDX-1 directly interacts with the INGAP promoter.

Endogenous PDX-1 is selectively expressed in betacells of the mature endocrine pancreas. HIT-T15 cells are a transformed hamster beta-cell line. Western blot analysis for PDX-1 protein expression showed that HIT-T15 cells constitutively express PDX-1 which could be detected in both the cytoplasmic and the nuclear compartments of the cell (Fig. 5A, inset). Unlike the activation of the INGAP promoter seen in 293 cells, which have no detectable PDX-1 expression, transient transfection of the INGAP-

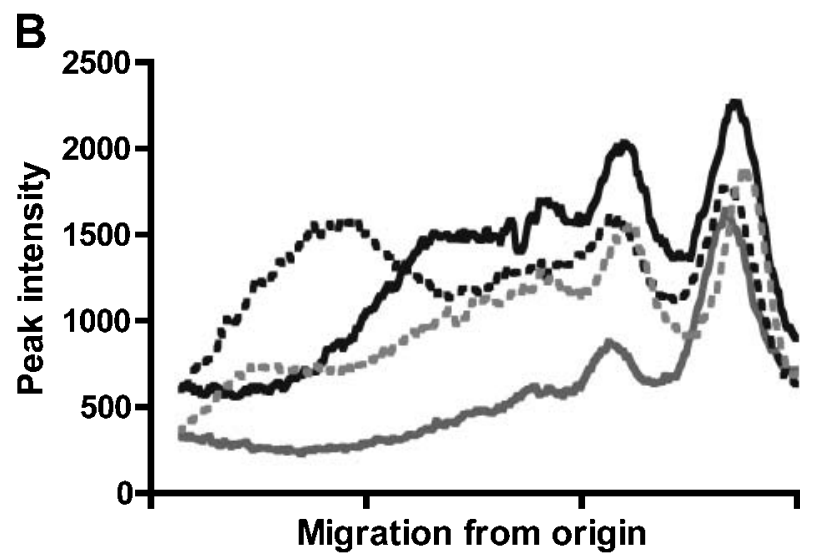

Figure 4 PDX-1 binds the INGAP promoter. EMSA of nuclear extracts from PDX-1 transfected 293 cells incubated with 20 fM labeled probe alone (a) or together with either $2 \mathrm{pM}$ unlabeled probe (b) or antibody specific for PDX-1 (c). Positions of shifted $\left({ }^{*}\right)$ and antibody-supershifted $\left(^{* *}\right)$ bands are marked on the gel (A) and densitometry analysis (B) of nuclear extracts incubated with either $20 \mathrm{fM}$ probe alone (solid black line), or with $2 \mathrm{pM}$ unlabeled probe (solid grey line), PDX-1 antibody (broken black line) or non-specific antibody (broken grey line).

reporter-promoter construct into the PDX-1-expressing HIT-T15 cells did not result in a basal expression of the $\beta$-galactosidase reporter gene. Further, stimulation with PMA of HIT-T15 cells transfected with the INGAPreporter-promoter resulted in no detectable expression of the $\beta$-galactosidase reporter gene, i.e. no detectable activation of the INGAP promoter. For both conditions, reporter expression was compared with that detected with a promoterless $\beta$-galactosidase reporter-construct (pBASIC, Fig. 5A). Transfection efficiency and PMA responsiveness were confirmed in the HIT-T15 cells. Transfection of HIT-T15 cells with pCMV-GFP, an expression plasmid for green fluorescent protein, under the identical protocol used for the INGAP-promoter reporter, resulted in a transfection efficiency in which greater than $68 \%$ of the cells expressed green fluorescent protein (GFP) when analyzed by flow cytometry (Fig. 5B). Cells were clearly positive for GFP as analyzed by immunofluorescence of pCMV-GFP transfected cells 
A
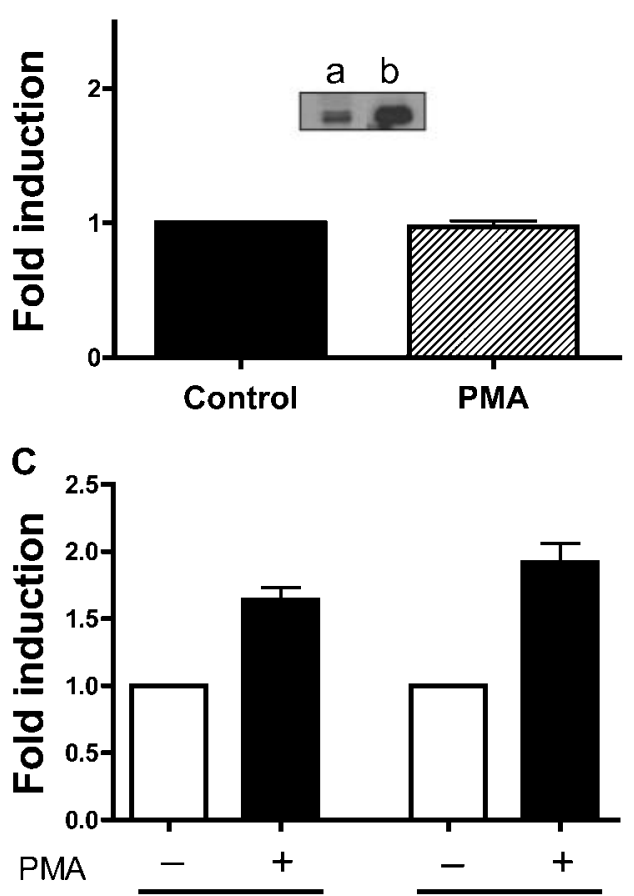

HIT-T15

\section{C}

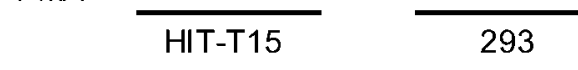

B

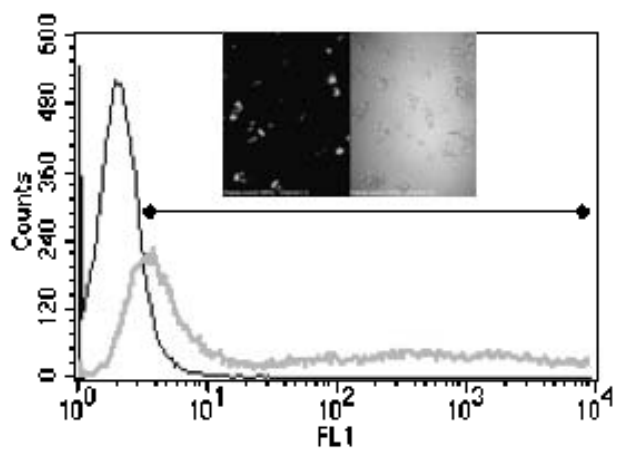

Figure 5 Suppression of INGAP-promoter-reporter activity in HIT-T15 cells. Beta-galactosidase reporter gene activity is shown for HIT-T15 cells (A) alone (filled) or stimulated with $50 \mathrm{ng} / \mathrm{ml} \mathrm{PMA} \mathrm{(hashed).} \mathrm{Inset} \mathrm{(A)}$ shows Western blot analysis for PDX-1 expression in HIT-T15 cytosol (a) nuclear (b) cell compartments. Expression of GFP in pCMV-GFP transfected HIT-T15 cells (B, bold line) is shown in comparison to mock-transfected HIT cells (faint line). Events falling in the fluorescent gate marked $\bullet$ ) were calculated. The inset micrograph shows fluorescent (left) and brightfield (right) of pCMV-GFP transfected cells. CAT reporter activity in HIT-T15 and 293 cells transfected with pAP1-CAT and stimulated with $50 \mathrm{ng} / \mathrm{ml}$ PMA (filled bars) is shown in (C).

(Fig. 5B, inset). HIT-T15 cells were also transfected with the reporter plasmid pAP-1-CAT. PMA stimulation of pAP-1-CAT-HIT-T15 cells resulted in a two-fold increase in CAT reporter gene activity (Fig. 5C). The plasmid pAP-1-CAT is a reporter construct in which tandem AP-1 consensus binding sites are upstream of a chloramphenicol acetyl transferase reporter gene. These data show that HIT-T15 cells both transfect efficiently and are responsive to PMA induced signaling. Introduction of the pAP1-CAT promoter-reporter plasmid into 293 cells resulted in an equivalent two-fold induction in CAT activity following stimulation with PMA (Fig. 5C). Thus, in contrast to 293 cells, the intracellular environment of HIT-T15 cells does not permit PMA-mediated stimulation of the INGAP promoter. HIT-T15 cells can however, be transfected and are responsive to PMA as a stimulus of gene expression. To reduce the expression of endogenous PDX-1 in HIT-T15 cells, siRNA for hamster PDX-1 sequence 573-593 (Genbank sequence U73854) was introduced. PDX-1 expression was analyzed by
Western blot analysis. The siRNA-PDX-1, but not a control siRNA probe (data not shown), reduced the protein expression level of PDX-1 by $60 \pm 15 \%$ (Fig. 6 A). The expression of the housekeeping gene tubulin was not affected by siRNA-PDX-1. Stimulation of the INGAPpromoter by PMA was tested in siRNA-PDX-1 treated HIT-T15 cells. Reporter-gene activity was increased $0 \cdot 62 \pm 0 \cdot 1$ fold in HIT cells treated with siRNA-PDX-1 that had a reduced expression of PDX-1. The increase seen was only in response to PMA stimulation, no increase in basal reporter gene activity was detected. To determine if the partial reduction in PDX-1 expression could explain the partial recovery of reporter gene activity to PMA in HIT-siRNA-PDX cells, PDX inhibition of PMAmediated activation of the INGAP-promoter-reporter gene was established in 293 cells (Fig. 6B). Decreasing amounts of pBat12 PDX-1 were transfected into 293 cells and the plasmid backbone (pBAT12) was used to standardize the DNA transfection ratios. PMA stimulation of the INGAP-reporter gene was dose-dependently 


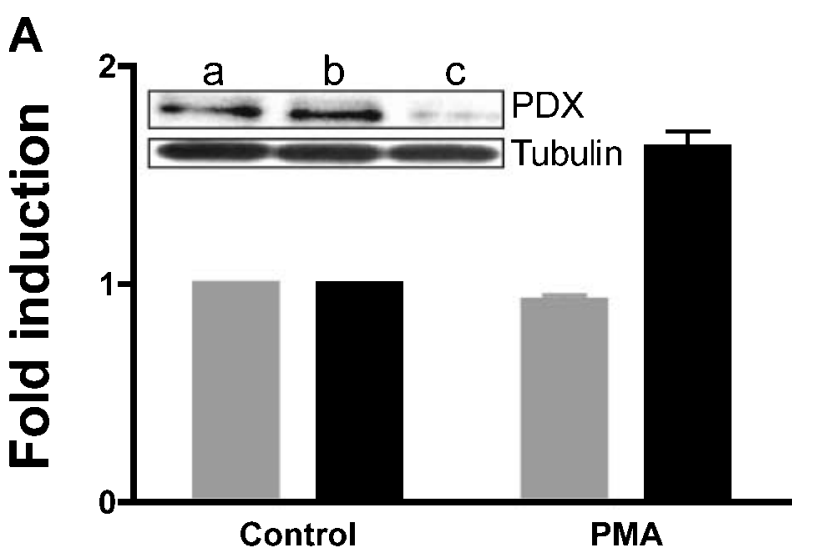

B PMA

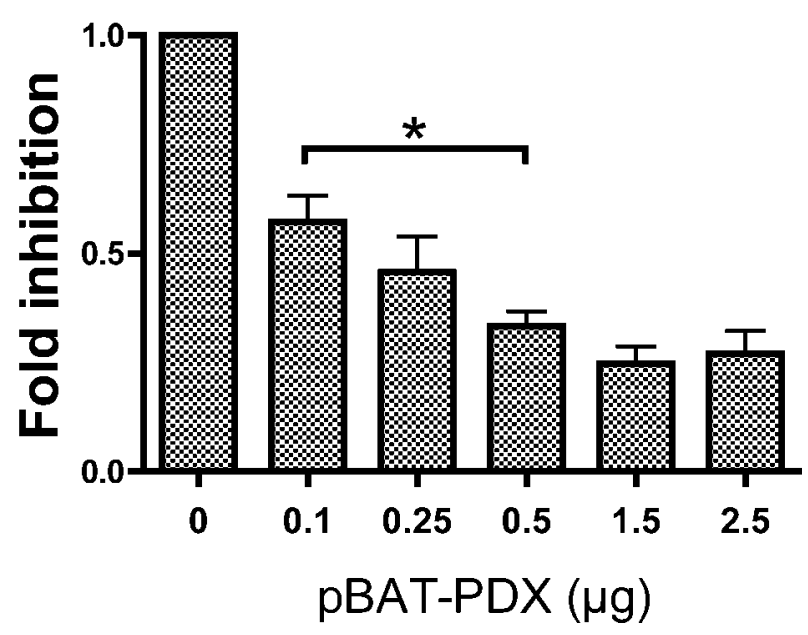

Figure 6 Knockdown of PDX-1 expression restores INGAPpromoter-reporter activity in HIT-T15 cells. (A) Expression of siRNA-PDX in HIT cells reduced the expression of PDX-1 (insert) but not tubulin. HIT-T15 cells were untreated (a) or treated with $1 \mu \mathrm{g}$ (b) or $2 \mu \mathrm{g}$ (c) siRNA-PDX. Response to PMA (50 ng/ml) in cells treated with $2 \mu \mathrm{g}$ siRNA-PDX (black bars) or control siRNA (grey bars) was assessed. Fold induction relative to non PMA stimulated cells is shown. (B) Dose dependency of PDX-1 expression on inhibition of PMA-induced stimulation of the INGAP-promoter-reporter in 293 cells is shown. Cells were transfected with $3 \mu \mathrm{g}$ of plasmid DNA (pBAT12 and pBAT12 PDX-1 plasmid) in the amounts shown. Cells were stimulated with PMA at $50 \mathrm{ng} / \mathrm{ml}$. Significant in dose-dependent reduction of the PMA response in marked (* $P<0.05)$.

inhibited by PDX-1. A partial recovery of the PMA response correlated with reduced amounts of PDX-1 transfected $(P<0 \cdot 05, t$-test). Collectively, these data imply the presence of a feedback inhibition of INGAP promoter activity mediated by PDX-1 in HIT-T15 cells.

\section{Discussion}

The studies described in this report show that PDX-1 can directly modulate INGAP promoter activity. Expression experiments in 293 cells reveal that PDX-1 binds to the INGAP promoter and inhibits gene expression when stimulated by the agents PAN-1, PMA and LIF. The stimulus response of the INGAP promoter is absent in HIT-T15 cells that have a constitutive expression of PDX-1. This response can be partially recovered by knocking down PDX-1 expression. Transcriptional control of INGAP by PDX-1 may clarify a mechanism to regulate induced islet mass.

In the studied transfection model, NeuroD, PDX-1 and PAN-1 increased INGAP promoter-mediated gene expression. The greatest stimulation of INGAP promoter activity was observed with PAN-1 which resulted in a five-fold induction in INGAP promoter mediated gene expression. The enhanced efficacy of PAN-1 compared with PDX-1 is unlikely to reflect greater occupancy on the INGAP promoter since more PDX-1 sites are predicted in the INGAP promoter region assayed. The homodimeric/heterodimeric properties and non-specific nature of PAN-1 in its DNA interaction (Dumonteil et al. 1998, Poulin et al. 2000, Qiu et al. 2002) suggest that PAN-1 could exert its action by interaction with a binding partner present in 293 cells. The identification of a protein partner is being investigated. Previous interactions of PAN-1 with PDX-1 and NeuroD have been reported (Ohneda et al. 2000). For the insulin gene, these interactions involve co-operative DNA-binding and synergy for gene induction. Whether these interactions are relevant to the regulation of INGAP were explored in a multi-factor transfection model. It was a surprise to discover that PDX-1 inhibited PAN-1-mediated activation of the INGAP-promoter rather than enhancing promoter stimulation. There are two possible explanations of this result: (1) either PDX-1 is interacting with PAN-1 or a PAN-1-binding partner to sequester a PAN-1 and/or PAN-1-binding partner away from a functional DNAbinding complex or (2) PDX-1 directly interacts with the INGAP promoter and induces a conformational change that is inhibitory to additional stimulus-induced transcription. Using the electromobility gel shift assay, PDX-1 was shown to interact with the INGAP promoter, suggesting the mechanism of PDX-1-mediated inhibition is by direct DNA interference. To strengthen this concept, the consequence of PDX-1 expression in distinct models for stimulating the INGAP promoter were explored. The phorbol ester, PMA and the cytokine, LIF induce signaling pathways and transcription cascades that are distinct to activation mediated by PAN-1. While PMA and LIF induce INGAP-promoter activity in 293 cells, the introduction of PDX-1 into 293 cells inhibited INGAPpromoter activity stimulated by PMA or LIF. Furthermore, INGAP promoter activity could not be stimulated by PMA in cells that endogenously express PDX-1, even though these cells transfect efficiently and are responsive to PMA-mediated stimuli, both in the studies shown in this report and those of others (Goodison et al. 1992, 
Yaney et al. 2002). Whereas, a reduction in the expression of endogenous PDX-1, using a siRNA knockdown strategy, partially restored the ability of PMA to activate the INGAP promoter. The absence of a complete knockdown of PDX-1 is likely to explain the partial recovery of the PMA response and the sustained absence of the basal response in HIT-T15 cells. Efforts to eliminate PDX-1 expression in HIT cells through repeated treatments with siRNA-PDX, or by the generation of a HIT cell line stably expressing siRNA-PDX (not shown) have been ineffective and may reflect the importance of a basal PDX-1 expression, for the maintenance of these cells. Furthermore, the hypothesis that a partial expression of PDX-1 could correlate with a partial inhibition at the INGAP promoter was reproduced in 293 cells. Thus, the data indicate that PDX-1 exerts a direct negative influence on the INGAP promoter such that in the presence of PDX-1 the INGAP promoter may be unresponsive to additional stimuli.

PDX-1 expression is implicated in the development of the pancreas (Jonsson et al. 1994, Stoffers et al. 1997), in lineage commitment (Edlund 2001) and in homeostasis of the mature beta-cells of the endocrine pancreas (Ahlgren et al. 1998). Thus, the functional implication of the observations made in this report may impact the regulation of INGAP expression both in development and/or in preserving the integrity of functional islet mass. INGAP is present in the pancreatic anlage during embryogenesis (Rafaeloff et al. 1998, N S Hamblet, A M Bowman, D A Taylor-Fishwick, unpublished observations), suggesting INGAP may have a role in the regulation of cell commitment, differentiation and/or expansion of the developing pancreas. During pancreas organogenesis it is possible that PDX-1 expression may serve to restrict INGAP expression. Additionally, the recent identification of INGAP expressing cells within the mature endocrine pancreas (Flores et al. 2003, Taylor-Fishwick et al. 2004) raises the possibility that the actions of INGAP may not be restricted to the expansion of islet mass. INGAP expression in the endocrine region of the pancreas is mutually exclusive to the PDX-1 expressing beta-cell. Immunoreactivity for INGAP and the alpha cell marker glucagon has been shown to co-localize in islets (Flores et al. 2003, Taylor-Fishwick et al. 2004). It is therefore feasible that an interaction between PDX-1 and INGAP expression is important in endocrine lineage commitment, such that expression of PDX-1 is associated with repression of INGAP expression. Moreover, evidence for a cross-talk signal originating from the beta-cell and regulating the expression of INGAP can be inferred in the studies of Takatori et al. (2003) which showed an increase in INGAP mRNA following destruction of beta-cells with the toxin streptozotocin.

Could PDX-1 have a role in regulating INGAP-mediated islet neogenesis in the mature pancreas? In models of islet neogenesis, surgical occlusion of the pancreatic duct or administration of exogenous INGAP, unbridled expansion of islet mass has not been observed (Gold et al. 1998, Rosenberg 1998, Rosenberg et al. 2004). Clearly negative feedback mechanism(s) exist to avoid unregulated generation of new islet mass. The attraction in our findings of PDX-1 exerting a negative role on INGAP expression lies in the simplicity of this direct feedback model. Precedent for a simple feedback loop involving PDX-1 does exist. PDX-1 binds to its own promoter and is implicated in a direct negative loop controlling its own expression (Marshak et al. 2000). Other regulating mechanism(s) must also exist to downregulate INGAP-driven islet neogenic signals. These are likely to be at the level of the INGAP receptor since administration of exogenous INGAP bypasses a negative feedback based upon repression of endogenous INGAP expression. Administration of exogenous INGAP upregulates PDX-1 expression in pancreatic ductal cells (Rosenberg et al. 2004) and ductal PDX-1 expression is a purported marker of precursor islet stem cells (Gagliardino et al. 2003), the cells most likely to be expressing the INGAP receptor.

Diabetes results from a loss of the functional beta-cell mass. Significant restrictions in organ supply and toxicity associated with long-term immunosuppression currently present major limitations to exogenous islet repopulation strategies (Hirshberg et al. 2003). Islet regeneration achieved by reprogramming endogenous pathways within the pancreas present an intriguing paradigm to repopulating the functional islet mass in the diabetic pancreas. As INGAP appears to function as part of a neogenic cascade, additional and equally attractive molecular targets are the regulators of INGAP expression, both for their theoretical potential as novel therapies for diabetes and for providing a more complete understanding of the processes governing neogenesis and pancreas organogenesis. Knowledge of the events governing INGAP expression, as reported herein, opens opportunities towards the realization of rational treatments for diabetes.

\section{Funding}

This research was sponsored through grants from the Diabetes Institutes Foundation, Cosmopolitan International and GMP Companies Inc. The authors declare that there is no conflict of interest that would prejudice the impartiality of this scientific work.

\section{References}

Ahlgren U, Jonsson J, Jonsson L, Simu K \& Edlund H 1998 betacell-specific inactivation of the mouse Ipf1/Pdx1 gene results in loss of the beta-cell phenotype and maturity onset diabetes. Genes and Development 12 1763-1768.

Bell GI \& Polonsky KS 2001 Diabetes mellitus and genetically programmed defects in beta-cell function. Nature 414 788-791. 
Bonner-Weir S, Baxter LA, Schuppin GT \& Smith FE 1993 A second pathway for regeneration of adult exocrine and endocrine pancreas. A possible recapitulation of embryonic development. Diabetes 42 1715-1720.

Borelli MI, Stoppiglia LF, Rezende LF, Flores LE, Del Zotto H, Boschero AC \& Gagliardino JJ 2005 INGAP-related pentadecapeptide: Its modulatory effect upon insulin secretion. Regulatory Peptides 131 97-102.

Bradford MM 1985 A rapid and sensitive method for the quantitation of microgram quantities of protein utilizing the principle of protein-dye binding. Analytical Biochemistry 151 369-374.

Brand SJ, Tagerud S, Lambert P, Magil SG, Tatarkiewicz K, Doiron K \& Yan Y 2002 Pharmacological treatment of chronic diabetes by stimulating pancreatic beta-cell regeneration with systemic co-administration of EGF and gastrin. Pharmacology and Toxicology 91 414-420.

Cartharius K, Frech K, Grote K, Klocke B, Haltmeier M, Klingenhoff A, Frisch M, Bayerlein M \& Werner T 2005 MatInspector and beyond: promoter analysis based on transcription factor binding sites. Bioinformatics 21 2933-2942.

Del Zotto H, Massa L, Rafaeloff R, Pittenger GL, Vinik A, Gold G, Reifel-Miller A \& Gagliardino JJ 2000 Possible relationship between changes in islet neogenesis and islet neogenesis-associated protein-positive cell mass induced by sucrose administration to normal hamsters. Journal of Endocrinology 165 725-733.

Dor Y, Brown J, Martinez OI \& Melton DA 2004 Adult pancreatic beta-cells are formed by self-duplication rather than stem-cell differentiation. Nature 429 41-46.

Dumonteil E, Laser B, Constant I \& Philippe J 1998 Differential regulation of the glucagon and insulin I gene promoters by the basic helix-loop-helix transcription factors E47 and BETA2. Journal of Biological Chemistry 273 19945-19954.

Edlund H 2001 Developmental biology of the pancreas. Diabetes 50 (Suppl 1) S5-S9.

Flanagan JG \& Cheng HJ 2000 Alkaline phosphatase fusion proteins for molecular characterization and cloning of receptors and their ligands. Methods in Enzymology 327 198-210.

Flores LE, Garcia ME, Borelli MI, Del Zotto H, Alzugaray ME, Maiztegui B \& Gagliardino JJ 2003 Expression of islet neogenesisassociated protein in islets of normal hamsters. Journal of Endocrinology 177 243-248.

Gagliardino JJ, Del Zotto H, Massa L, Flores LE \& Borelli MI 2003 Pancreatic duodenal homeobox-1 and islet neogenesis-associated protein: a possible combined marker of activateable pancreatic cell precursors. Journal of Endocrinology 177 249-259.

German MS \& Wang J 1994 The insulin gene contains multiple transcriptional elements that respond to glucose. Molecular and Cellular Biology 14 4067-4075.

Gold G, Broderick C, Caragna M, Williams G, Pittenger GL, Rafaeloff R, Reifel-Miller A, Borts T, Hale J, Churgay L et al. 1998 INGAP treatment improves glycemic control in streptozotocin diabetic hamsters. Diabetes 47 A253.

Goodison S, Kenna S \& Ashcroft SJ 1992 Control of insulin gene expression by glucose. Biochemistry Journal 285 563-568.

Hirshberg B, Rother KI \& Harlan DM 2003 Islet transplantation: where do we stand now? Diabetes Metabolism Research Reviews 19 175-178.

Holz GG \& Chepurny OG 2003 Glucagon-like peptide-1 synthetic analogs: new therapeutic agents for use in the treatment of diabetes mellitus. Current Medical Chemistry 10 2471-2483.

Huang HP, Liu M, El-Hodiri HM, Chu K, Jamrich M \& Tsai MJ 2000 Regulation of the pancreatic islet-specific gene BETA2 (neuroD) by neurogenin 3. Molecular and Cellular Biology 20 3292-3307.

Jamal AM, Lipsett M, Sladek R, Laganiere S, Hanley S \& Rosenberg L 2005 Morphogenetic plasticity of adult human pancreatic islets of Langerhans. Cell Death and Differentiation 12 702-712.
Jonsson J, Carlsson L, Edlund T \& Edlund H 1994 Insulin-promoterfactor 1 is required for pancreas development in mice. Nature 371 606-609.

Kim BM, Han YM, Shin YJ, Min BH \& Park IS 2001 Clusterin expression during regeneration of pancreatic islet cells in streptozotocin-induced diabetic rats. Diabetologia 44 2192-2202.

Li M, Miyagawa J, Yamamoto K, Moriwaki M, Imagawa A, Iwahashi H, Yamagata K, Tochino Y, Hanafusa T \& Matsuzawa Y 2002 Beta-cell neogenesis from ducts and phenotypic conversion of residual islet cells in the adult pancreas of glucose intolerant mice induced by selective alloxan perfusion. Endocrine Journal 49 561-572.

Marshak S, Benshushan E, Shoshkes M, Havin L, Cerasi E \& Melloul D 2000 Functional conservation of regulatory elements in the pdx-1 gene: PDX-1 and hepatocyte nuclear factor 3 beta transcription factors mediate beta-cell-specific expression. Molecular and Cellular Biology 20 7583-7590.

Mathis D, Vence L \& Benoist C 2001 beta-Cell death during progression to diabetes. Nature 414 792-798.

Mutoh H, Fung BP, Naya FJ, Tsai MJ, Nishitani J \& Leiter AB 1997 The basic helix-loop-helix transcription factor BETA2/NeuroD is expressed in mammalian enteroendocrine cells and activates secretin gene expression. PNAS 94 3560-3564.

Naya FJ, Huang HP, Qiu Y, Mutoh H, DeMayo FJ, Leiter AB \& Tsai MJ 1997 Diabetes, defective pancreatic morphogenesis, and abnormal enteroendocrine differentiation in BETA2/neuroDdeficient mice. Genes Development 11 2323-2334.

Ohneda K, Mirmira RG, Wang J, Johnson JD \& German MS 2000 The homeodomain of PDX-1 mediates multiple protein-protein interactions in the formation of a transcriptional activation complex on the insulin promoter. Molecular and Cellular Biology 20 900-911.

Okamoto H 1999 The Reg gene family and Reg proteins: with special attention to the regeneration of pancreatic beta-cells. Journal of Hepatobiliary Pancreatic Surgery 6 254-262.

Peters K, Panienka R, Li J, Kloppel G \& Wang R 2005 Expression of stem cell markers and transcription factors during the remodeling of the rat pancreas after duct ligation. Virchows Archives 446 56-63.

Poulin G, Lebel M, Chamberland M, Paradis FW \& Drouin J 2000 Specific protein-protein interaction between basic helix-loop-helix transcription factors and homeoproteins of the Pitx family. Molecular and Cellular Biology 20 4826-4837.

Qiu Y, Guo M, Huang S \& Stein R 2002 Insulin gene transcription is mediated by interactions between the p300 coactivator and PDX-1, BETA2, and E47. Molecular and Cellular Biology 22 412-420.

Rafaeloff R, Pittenger GL, Barlow SW, Qin XF, Yan B, Rosenberg L, Duguid WP \& Vinik AI 1997 Cloning and sequencing of the pancreatic islet neogenesis associated protein (INGAP) gene and its expression in islet neogenesis in hamsters. Journal of Clinical Investigation 99 2100-2109.

Rafaeloff R, Schmitt E, Edlund H, Gold G \& Vinik A 1998 Expression of INGAP during ontogeny of the pancreas. Diabetes 47 A259.

Rosenberg L 1998 Induction of islet cell neogenesis in the adult pancreas: the partial duct obstruction model. Microscopic Research Techniques 43 337-346.

Rosenberg L, Duguid WP \& Vinik AI 1989 The effect of cellophane wrapping of the pancreas in the Syrian golden hamster: autoradiographic observations. Pancreas 4 31-37.

Rosenberg L, Lipsett M, Yoon JW, Prentki M, Wang R, Jun HS, Pittenger GL, Taylor-Fishwick D \& Vinik AI 2004 A pentadecapeptide fragment of islet neogenesis-associated protein increases beta-cell mass and reverses diabetes in C57BL/6J mice. Annals of Surgery 240 875-884.

Ryan EA, Lakey JR, Paty BW, Imes S, Korbutt GS, Kneteman NM, Bigam D, Rajotte RV \& Shapiro AM 2002 Successful islet transplantation: continued insulin reserve provides long-term glycemic control. Diabetes $\mathbf{5 1} 2148-2157$. 
Stoffers DA, Zinkin NT, Stanojevic V, Clarke WL \& Habener JF 1997 Pancreatic agenesis attributable to a single nucleotide deletion in the human IPF1 gene coding sequence. Nature Genetics 15 106-110.

Takatori A, Ohta E, Inenaga T, Horiuchi K, Ishii Y, Itagaki S, Kyuwa S \& Yoshikawa Y 2003 Protective effects of probucol treatment on pancreatic beta-cell function of SZ-induced diabetic APA hamsters. Experiments in Animals 52 317-327.

Taylor-Fishwick DA, Kendall H, Ray M, Roy L, Cao Y, Pittenger GL, Rosenberg L \& Vinik AI 2002 Induction of INGAP expression through an activator of protein kinase $\mathrm{C}$ and cytokineinduced STAT signalling. Diabetes $\mathbf{5 1}$ A372.

Taylor-Fishwick DA, Rittman S, Kendall H, Roy L, Shi W, Cao Y, Pittenger GL \& Vinik AI 2003 Cloning genomic INGAP: a Reg-related family member with distinct transcriptional regulation sites. Biochimica et Biophysica Acta 1638 83-89.
Taylor-Fishwick DA, Bowman A \& Vinik AI 2004 Evidence for peri-islet (alpha cell) expression of INGAP. Diabetes 53 A403.

UKPDSGroup 1995 U.K. prospective diabetes study 16. Overview of 6 years' therapy of type II diabetes: a progressive disease. U.K. Prospective Diabetes Study Group. Diabetes 44 1249-1258.

Vinik AI, Rosenberg L, Pittenger GL \& Taylor-Fishwick DA 2004 Stimulation of pancreatic islet neogenesis: a possible treatment for type 1 and type 2 diabetes. Current Opinions in Endocrinology and Diabetes 11 125-140.

Yaney GC, Fairbanks JM, Deeney JT, Korchak HM, Tornheim K \& Corkey BE 2002 Potentiation of insulin secretion by phorbol esters is mediated by PKC-alpha and nPKC isoforms. American Journal of Physiology, Endocrinology and Metabolism 283 E880-E888.

Received 21 November 2005

Accepted 8 December 2005 